Sensitivity of Southern Ocean circulation to wind stress changes:

Role of relative wind stress

D.R. Munday, X. Zhai

PII:

S1463-5003(15)00157-2

DOI:

Reference:

OCEMOD 1018

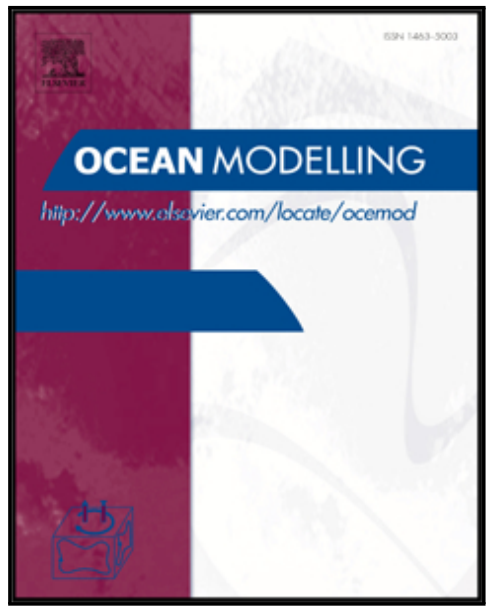

To appear in:

Ocean Modelling

Received date:

10 April 2015

Revised date:

6 August 2015

Accepted date:

14 August 2015

Please cite this article as: D.R. Munday, X. Zhai, Sensitivity of Southern Ocean circulation to wind stress changes: Role of relative wind stress, Ocean Modelling (2015), doi: 10.1016/j.ocemod.2015.08.004

This is a PDF file of an unedited manuscript that has been accepted for publication. As a service to our customers we are providing this early version of the manuscript. The manuscript will undergo copyediting, typesetting, and review of the resulting proof before it is published in its final form. Please note that during the production process errors may be discovered which could affect the content, and all legal disclaimers that apply to the journal pertain. 


\section{Highlights}

- Dynamic impacts of relative wind stress and resting ocean approximations on the Southern Ocean are tested.

- Damping of the eddy field with relative wind stress has a stronger impact upon EKE than the reduction in mean wind stress.

- At same mean wind stress, relative wind stress produces colder sea surface temperatures than the resting ocean approximation.

- Sensitivity to changing wind stress of the RMOC is the same due to balancing changes in eddy diffusivity and isopycnal slope. 


\title{
Sensitivity of Southern Ocean circulation to wind stress changes: Role of relative wind stress
}

\author{
D.R. Munday ${ }^{\mathrm{a}, \mathrm{b}, *}$, X. Zhai ${ }^{\mathrm{c}, \mathrm{d}}$ \\ ${ }^{a}$ British Antarctic Survey, High Cross, Madingley Road, Cambridge, CB3 OET, UK \\ ${ }^{b}$ Atmospheric, Oceanic and Planetary Physics, Department of Physics, University of \\ Oxford, Oxford, OX1 3PU, UK \\ ${ }^{c}$ School of Environmental Sciences, University of East Anglia, Norwich, UK. \\ ${ }^{d}$ School of Marine Science, Nanjing University of Information Science and Technology,
} Nanjing, China.

\begin{abstract}
\end{abstract}
The influence of different wind stress bulk formulae on the response of the Southern Ocean circulation to wind stress changes is investigated using an idealised channel model. Surface/mixed layer properties are found to be sensitive to the use of the relative wind stress formulation, where the wind stress depends on the difference between the ocean and atmosphere velocities. Previous work has highlighted the surface eddy damping effect of this formulation, which we find leads to increased circumpolar transport. Nevertheless the transport due to thermal wind shear does lose sensitivity to wind stress changes at sufficiently high wind stress. In contrast, the sensitivity of the meridional overturning circulation is broadly the same regardless of the bulk formula used due to the adiabatic nature of the relative wind stress damping. This is a consequence of the steepening of isopycnals offsetting the reduction

${ }^{*}$ Corresponding author

Email addresses: danday@bas.ac.uk (D.R. Munday), xiaoming.zhai@uea.ac.uk (X. Zhai) 
in eddy diffusivity in their contribution to the eddy bolus overturning, as predicted using a residual mean framework.

Keywords: Ocean modelling, Relative wind stress, Wind forcing, Eddy saturation, Eddy Compensation

\section{Introduction}

2 The transfer of momentum between the atmosphere and ocean is usually

3 parameterised as a stress applied at the surface. Arguments originating from

4 the theory of vertical turbulent transfers give rise to the following expression

5 for the applied stress

$$
\boldsymbol{\tau}_{\text {relative }}=\rho_{a} c_{d}\left|\mathbf{U}_{10}-\mathbf{u}_{s}\right|\left(\mathbf{U}_{10}-\mathbf{u}_{s}\right)
$$

7 where $\mathbf{U}_{10}=\left(U_{10}, V_{10}\right)$ is the $10 \mathrm{~m}$ (atmospheric) wind velocity, $\mathbf{u}_{s}=\left(u_{s}, v_{s}\right)$

8 is the surface ocean velocity, $\rho_{a}$ is air density, and $c_{d}$ is a drag coefficient,

9 which itself may be a weak function of $\mathbf{U}_{10}-\mathbf{u}_{s}$. We will refer to the use of

$$
\boldsymbol{\tau}_{\text {resting }}=\rho_{a} c_{d}\left|\mathbf{U}_{10}\right| \mathbf{U}_{10} .
$$

The use of relative wind stress leads to a slight decrease in the stress felt by the ocean, relative to the resting ocean approximation. This contributes to a reduction of the power input to the ocean circulation by $\sim 20-35 \%$ 2008; Zhai et al., 2012). Since the power input from the wind is a major source 
42 In residual mean theory, the streamfunction of the RMOC is written as 43 the combination of the Eulerian mean $\operatorname{MOC}(\bar{\Psi})$ and the eddy-induced bolus

of energy to the ocean (Wunsch and Ferrari, 2004; Ferrari and Wunsch, 2009) this could have significant consequences for the large-scale ocean circulation, its variability, and its sensitivity to changes in surface wind stress.

Relative wind stress exerts a torque on individual eddies that opposes their circulation and so directly damps them. This is due to the increase in the velocity difference between ocean and atmosphere from one side of the eddy to the other (see Fig. 1 of Zhai et al., 2012). This acts as a drag at the surface of the ocean and significantly increases the rate of spindown of waves and eddies via the introduction of "top friction" (Dewar and Flierl, 1987). In regions in which mesoscale eddies play an important role in ocean circulation/dynamics, such as the Southern Ocean, this could indicate an important role for relative wind stress.

The Southern Ocean is subject to strong atmospheric winds and makes a large regional contribution to the global integral of mechanical power input to the ocean (Wunsch, 1998). It has a strong influence on global climate, via its Residual Meridionar Qverturning Circulation (RMOC) and the Antarctic Circumpolar Current (ACC) (Meredith et al., 2011). Mesoscale eddies play prominent roles in the momentum (Munk and Palmén, 1951; Johnson and Bryden, 1989), heat (Bryden, 1979; Jayne and Marotzke, 2002; Meijers et al., 2007) and kinetic energy (Cessi et al., 2006; Cessi, 2008; Abernathey et al., 2011) budgets of the Southern Ocean. The role that relative wind stress might play in the dynamics and circulation of the Southern Ocean can be usefully framed in terms of a residual mean treatment of the RMOC. 
44

64

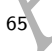

66

67

overturning $\left(\Psi^{*}\right)$ (see, e.g., Marshall and Radko, 2003), i.e.

$$
\Psi_{\mathrm{res}}=\bar{\Psi}+\Psi^{*}=-\frac{\bar{\tau}_{x}}{\rho_{0} f}+K s
$$

In Eq. (3), $\bar{\tau}_{x}$ is the time-mean zonal wind stress, $\rho_{0}$ is the Boussinesq reference density, $f$ is the Coriolis parameter, $K$ is the quasi-Stokes/eddy diffusivity for the buoyancy field $\left(b=-g\left(\rho-\rho_{0}\right) / \rho_{0}\right)$ and $s=-\bar{b}_{y} / \bar{b}_{z}$ is the isopycnal slope. There are a considerable number of ways to formulate the dependence of $K$ on external parameters. For the current purpose, the most informative is to use mixing length theory (Prandtl, 1925) to relate $K$ to the product of an eddy length and eddy velocity scale, i.e. $L_{\text {eddy }}$ and $U_{\text {eddy }}$, such that $K=L_{\text {eddy }} U_{\text {eddy }}$ (see, e.g., Green, 1970; Stone, 1972; Eden and Greatbatch, 2008).

In Eq. (3), it is the mean wind stress that plays a role in setting the residual overturning. Relative wind stress can therefore directly impact the residual overturning by reducing $\bar{\tau}_{x}$. Furthermore, the direct damping of the eddy field can be reasonably expected to alter both $L_{\text {eddy }}$ and $U_{\text {eddy }}$, i.e. $K$, and, hence, the eddy-induced bolus overturning and net RMOC. Intuition suggests that damping the eddy field will reduce $U_{\text {eddy }}$ and $K$, and hence $\Psi^{*}$.

A further indirect effect can also occur through the isopycnal slope, $s$, which can be related to the zonal volume transport of the ACC via thermal wind. Eddies play a large role in setting the stratification of the ocean (e.g. Karsten et al., 2002) as part of a dynamic balance with other processes. Damping eddies at the surface may alter the balance between processes that set the stratification and so change $s$. This would then have a knock-on effect on the bolus overturning and zonal transport of the ACC. As an example, 

91 AMF11; ZM14; Morrison and Hogg, 2013; Munday et al., 2013). Applying

92 a constant wind stress is certainly within the idealised spirit and design of

in the quasi-geostrophic Southern Ocean simulations of Hutchinson et al. (2010) the use of relative wind stress results in a 38Sv increase in circumpolar transport. This comes about due to steepening of isopycnals and an increase in the geostrophic velocity field via thermal wind shear.

The above discussion is framed in terms of a particular wind stress and the ocean circulation/stratification that results. However, when the wind stress over the Southern Ocean changes, the mesoscale eddy field also responds. This leads to a decrease in the sensitivity of the circumpolar transport of the ACC (Hallberg and Gnanadesikan, 2001; Tansley and Marshall, 2001) and of the RMOC (Hallberg and Gnanadesikán, 2006; Farneti et al., 2010) to changes in wind stress when the eddy field is resolved instead of parameterised. These phenomena are known as eddy saturation (Straub, 1993) and eddy compensation (Viebahn and Eden, 2010), respectively. Although there are subtleties to the degree of eddy saturation/compensation that a particular model may exhibit, e.g. the presence of shallow coastal shelves (Hogg and Munday, 2014) or surface breaking continents (Munday et al., 2015) and the use of fixed heat/buoyancy fluxes vs. restoring to a fixed temperature/buoyancy profile (Abernathey et al., 2011; Zhai and Munday, 2014, henceforth AMF11 and ZM14, respectively), their emergence upon resolution of an eddy field is robust in many respects.

Many of the above cited papers use idealised model configurations to investigate the effect changing wind stress on circumpolar transport and/ or the RMOC. In doing so, they usually use a specified wind stress (e.g. within the idealised spirit and design of 


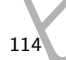

such experiments. However, it rules out the direct damping of the mesoscale eddy field that takes place under relative wind stress and the role that this might play in setting the sensitivity of the RMOC and/or stratification to changing winds.

In this paper we seek to answer the following questions: 1) can the impact of relative wind stress be modelled simply by accounting for the reduced mean wind stress? 2) does the direct damping of the mesoscale eddy field have implications for Southern Ocean dynamics? 3) does relative wind stress significantly alter the sensitivity of the circumpolar transport and the RMOC to wind stress changes?

We begin in Section 2 with a brief description of the experimental design and model domain. The control simulations of three suites of experiments are discussed in Section 3. Section 4 briefly derives a simplified mechanical energy budget for the ocean including the effects of relative wind stress. The sensitivity to wind stress changes across the full suite of experiments is discussed in Section 5. We close with a summary and discussion of our results in Section 6 .

\section{Experimental Design}

[Table 1 about here.]

In order to investigate the impact of relative wind stress, and its associated eddy damping effects, on Southern Ocean dynamics we adopt the idealised MIT general circulation model (MITgcm, see Marshall et al., 1997a,b) configuration of AMF11, adapted to a coarser grid spacing by ZM14. This model domain is a zonally re-entrant channel that is $1000 \mathrm{~km}$ in zonal extent, 
nearly $2000 \mathrm{~km}$ in meridional extent, and $2985 \mathrm{~m}$ deep with a flat bottom. There are 33 geopotential levels whose thickness increase with depth, ranging from $10 \mathrm{~m}$ at the surface to $250 \mathrm{~m}$ for the bottom-most level.

The horizontal grid spacing is chosen to be $10 \mathrm{~km}$, which is sufficiently fine so as to permit a vigorous eddy field without incurring undue computational cost. This grid spacing makes the model eddy-permitting, rather than éddyresolving, with the control wind stress (see below for forcing details) giving a first baroclinic Rossby radius in the range of $\sim 5 \mathrm{~km}$ near the southern boundary and $\sim 25 \mathrm{~km}$ near the northern. It is important to note that the eddies are generally several multiples of the deformation radius in size and that use of a $10 \mathrm{~km}$ grid spacing does not preclude the emergence of a high degree of eddy saturation (Munday et $a 1 ., 2015$ ) and as such we deem it sufficient for our purposes.

We employ the K-profile parameterisation (KPP) vertical mixing scheme (Large et al., 1994) and a linear bottom friction in addition to the much weaker drag from a noslip bottom boundary condition. The equation of state is linear and only temperature variations are considered. The model is set on a $\beta$-plane and lateral boundaries are noslip. Parameters values for bottom friction, viscosity, etc, are as given in Table 1.

The model's potential temperature, $\theta$, is forced by a heat flux at the surface given by

$$
Q(y)= \begin{cases}-Q_{0} \sin \left(3 \pi y / L_{y}\right), & \text { for } y<L_{y} / 3 \\ 0, & \text { for } y>L_{y} / 3\end{cases}
$$

39 as per AMF11 and ZM14, except $y=0 \mathrm{~km}$ is placed at the centre of the 
domain. This broadly describes the observed distribution of surface buoyancy flux around the Southern Ocean (see Fig. 1 of AMF11). Within 100km of the northern boundary, potential temperature is restored to the stratification given by

$$
\theta_{N}(z)=\Delta \theta\left(e^{z / h_{e}}-e^{-H / h_{e}}\right) /\left(1-e^{-H / h_{e}}\right)
$$

The restoring time scale for the sponge varies from $\infty$ (no restoring) at the southern edge of the sponge to 7 days at the northern edge of the domain. The surface buoyancy flux and sponge restoring profile are as shown in Figs. $1 \mathrm{a}$ and $1 \mathrm{~b}$.

\section{[Figure 1 about here.]}

In contrast to AMF11 and ZM14, we do not prescribe the wind stress in the majority of our experiments. Instead we prescribe wind velocity and use the bulk formulae of Large and Pond (1981), i.e. Eqs. (1) and (2), to calculate the wind stress. The wind velocity is given by

$$
\mathbf{U}_{10}=\mathbf{U}_{0} \cos \left(\pi y / L_{y}\right),
$$

where $\mathbf{U}_{0}=\left(U_{x}, U_{y}\right)$ is the peak wind velocity in the zonal and meridional direction. For the experiments considered here, the peak meridional wind, $U_{y}$, is set to zero and the peak zonal wind, $U_{x}$, varies from $0 \mathrm{~m} \mathrm{~s}^{-1}$ to $20 \mathrm{~m} \mathrm{~s}^{-1}$. Representative examples of the zonal wind that arises from Eq. (6) are shown in Fig. 1c.

In total, we have performed 3 sets of 8 experiments. The first 8 of these we refer to as the resting ocean experiments. These use peak zonal wind 
velocities of $0,3,7,10,12,16,18$, and $20 \mathrm{~m} \mathrm{~s}^{-1}$ with the resultant wind stress calculated as per Eq. (2). There is no meridional wind, and thus no meridional wind stress, in these experiments. The wind stresses that zonal wind velocities of 3,12 , and $20 \mathrm{~m} \mathrm{~s}^{-1}$ produce are shown in Fig. 1d.

We refer to the second set of 8 experiments as the relative wind stress experiments. These use the same peak zonal wind velocities as the resting ocean experiments, but Eq. (1) is used to calculate the wind stress. This gives a slight decrease in the peak zonal wind stress and introduces a very weak (absolute magnitude $\lesssim 0.05 \mathrm{~N} \mathrm{~m}^{-2}$ when $U_{x}=20 \mathrm{~ms}^{-1}$ ) meridional stress.

For the final set of 8 experiments, we use 50 year average of the zonal and meridional wind stress from the relative wind stress experiments to drive the ocean. This includes the very weak meridional stress. We refer to these as the equivalent wind stress experiments.

The resting ocean and relative wind stress experiments are begun from the statistically steady control experiment of ZM14 with the wind stress replaced with the wind velocities described above. They are run to their new statistical steady state. At the end of this phase of spin up we perform a 50 year diagnostic rum, from which all subsequent figures and conclusions are drawn. The 50 year average of the zonal and meridional wind stress diagnosed from this time period are then used to drive the equivalent wind stress experiments. These are run to their statistical steady state, after which an additional 50 year diagnostic run is carried out. 


\section{The Control State}

\subsection{Zonal Circulation of the Control State}

For our control experiments we select a peak zonal wind speed of $12 \mathrm{~m} \mathrm{~s}^{-1}$. This gives a peak zonal wind stress of $0.208 \mathrm{~N} \mathrm{~m}^{-2}$ for the relative wind stress and equivalent wind stress experiments, very close to the control wind stress used by AMF11 and ZM14 $\left(0.2 \mathrm{~N} \mathrm{~m}^{-2}\right)$. The peak zonal wind stress is slightly higher for the resting ocean experiments at $0.222 \mathrm{~N} \mathrm{~m}^{-2}$. Due to the flat bottom, the time-average circulation of all of our experiments is very close to zonally symmetric with mean streamlines closely aligned with contours of potential temperature (not shown).

Assuming a purely zonal time-mean wind stress, since $\bar{\tau}_{y} \ll \bar{\tau}_{x}$ for all of the relative and equivalent wind stress experiments, the depth-integrated zonal momentum budget of a flat bottomed channel is approximately (see, e.g. Gill and Bryan, 1971)

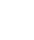

$$
\text { 然 }
$$

where the overbar indicates a time average, the angled braces an average in the zonal direction and the subscript $b$ indicates the bottom value. This approximate budget indicates that the bottom flow accelerates until the linear bottom friction can balance the momentum source at the surface. This leads to large zonal transport in models without bathymetry.

[Table 2 about here.]

205 On the basis of Eq. (7), the total circumpolar transport of the mean zonal flow $\left(T_{A C C}\right)$ can be decomposed into contributions due to changes in 
the bottom flow and that due to changes in thermal wind shear (see Munday et al., 2015, for details). We refer to the depth and zonal integral of $\left\langle\bar{u}_{b}\right\rangle$ as the "bottom transport" $\left(T_{b}\right)$ and the difference between this and the total transport as the "thermal wind transport", given by $T_{t w}=T_{A C C}-T_{b}$.

For the relative and equivalent wind stress control experiments, there is no difference in $T_{b}$ (see Table 2), as one would expect from Eq. (7). In the resting ocean control, the wind stress is increased and so, thereføre, is the resulting $T_{b}$. The increase in $T_{b}$ due to higher wind stress dominates the change in $T_{A C C}$ between the resting ocean control experiment and the other two controls. In contrast, for $T_{t w}$ the relative wind stress and resting ocean controls both show a $1 \mathrm{~Sv}$ increase with respect to the equivalent wind stress control. This is due to changes in isopycnal slope and the buoyancy change across the current (see Section 3.3 for further discussion).

\subsection{Residual Overturning of the Control State}

[Figure 2 about here.]

Following AMF11 and ZM14, the model's RMOC is diagnosed using potential temperature as the vertical coordinate. The calculations uses discrete layers that are $0.2^{\circ} \mathrm{C}$ thick and is interpolated back to depth coordinates on the model's geopotential layers. The eddy-induced bolus overturning, $\Psi^{*}$, can then be calculated using $\Psi^{*}=\Psi_{\text {res }}-\bar{\Psi}$, where $\bar{\Psi}$ is the Eulerian mean overturning.

The RMOC of all three control experiments closely resembles that of the control experiments of AMF11 and ZM14, as shown in Fig. 2. The Eulerian overturning is very similar for the relative wind stress and equivalent 
wind stress cases (not shown). Therefore, any significant difference between these two experiments arises through modification of the eddy-induced bolus overturning. The resting ocean experiment with the same wind speed has a slightly more intense Eulerian overturning due to the $7 \%$ increase in $\left\langle\overline{\tau_{x}}\right\rangle$.

In general, the differences between the control RMOCs in Figs. 2 are relatively minor. The upwelling North Atlantic Deep Water (NADW) cell (red) and the downwelling Antarctic Bottom Water (AABW) cell (blue, near the southern boundary) are all broadly the same strength and at roughly the same depth/temperature range. To quantify the strength of the cells, we use the same method as AMF11 and select the maximum and minimum value of $\Psi_{\text {res }}$ below $500 \mathrm{~m}$ and $100 \mathrm{~km}$ south of the edge of the sponge region. These values are labeled $\Psi_{\text {upper }}$ and $\Psi_{\text {lower }}$ for the NADW and AABW cells, respectively. For the three control experiments, the strength of the NADW and AABW cells are very similar at depth (see Table 2). This implies that there has not been a large-scale weakening of the eddy-induced bolus overturning due to the damping of the eddy field in the relative wind stress control experiment.

Examination of the-mixed layer, defined as above the depth at which the water is $0.8^{\circ} \mathrm{C}$ colder than the surface (above the grey line in Fig. 2, see, e.g., Kara et al., 2000, for details), indicates that this is the region where the biggest differences between the control experiments occur. To quantify the strength of the RMOC in the mixed layer we select the maximum value above $500 \mathrm{~m}$ and the minimum value above $500 \mathrm{~m}$, and within the southern half of the domain (to ensure selecting a value from the AABW cell). These measures are labeled $\Psi_{\mathrm{m}+}$ and $\Psi_{\mathrm{m}-}$, respectively, in Table 2 and are intended 

279 place at this altered temperature range. $\Psi_{\mathrm{m}-}$ values are only marginally different. the confines of the AABW cell.

to highlight any large-scale changes in the flow within the mixed layer. For the relative wind stress control experiment $\Psi_{\mathrm{m}+}=0.84 \mathrm{~Sv}$ and is $\sim 30 \%$ higher than for either of the other two control experiments. In contrast, the

Due to the relative and equivalent wind stress controls having the same Eulerian overturning, the reduced value $\Psi_{\mathrm{m}+}$ for the relative control must be due to a weaker eddy-induced bolus overturning within the mixed layer. The NADW cell is placed under the strongest wind forcing, where the damping of the eddy field by relative wind stress is also strongest. Hence, it is unsurprising that the largest changes to the RMOC take place in this locale. In contrast, the similar value of $\Psi_{\mathrm{m}-}$ for the relative and equivalent wind stress experiments imply that their bolus overturning is also similar within

Close examination of Fig. 2 reveals that whilst the distribution in depth coordinates is grossly the same, there are changes in the temperature distribution of the RMOC. For example, the $0.5^{\circ} \mathrm{C}$ isotherm is within the AABW cell for the relative wind stress control experiment. However, this isotherm is lower in the water column, and thus removed from the AABW cell in the other two control experiments. Within the NADW cell, which is where we focus most of our attention, the differences are much smaller. Damping of the eddy field alters the stratification and exposes different temperatures to difference heat and momentum fluxes at the surface. Since the RMOC must "match" this forcing (Walin, 1982; Badin and Williams, 2010), it has to take 
300

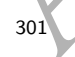

\subsection{Eddy Kinetic Energy and Vertical Stratification}

In terms of surface Eddy Kinetic Energy (EKE), the direct damping of the eddy field by relative wind stress is far more important than the slight decrease in mean wind stress with respect to the resting ocean approximation. This is illustrated in the surface EKE maps of Fig. 3a-c. The $\sim 3 \%$ decrease in surface average EKE between Figs. 3b and 3c is caused by the $7 \%$ reduction in mean wind stress between the equivalent wind stress and resting ocean control experiments. However, in Fig. 3a the-surface average EKE has decreased by a further $\sim 15 \%$, relative, to Fig. $3 b$.

[Figure 3 about here.]

[Figure 4 about here.]

The difference in EKE between the relative and equivalent wind stress experiments persists throughout the water column, as shown in Fig. 4a. This contrasts with the effect of surface heat flux damping of EKE, which is confined to roughly the top 100m (see Fig. 5a of ZM14). The magnitude of this difference decays with depth, such that it is not a simple step change throughout the domain. In contrast, temperature variance shows only a slight difference at mid-depths, with the surface and bottom values being very similar between the relative and equivalent wind stress experiments (see Fig. 4b).

In Fig. 5 it is noteworthy that the isotherms in the relative wind stress control (red lines) are nearly always steeper than the isotherms of the equivalent wind stress control (blue lines). Furthermore, they are also quite often steeper than the isotherms of the resting ocean control (green line), despite 
325

the weaker wind stress. This can be attributed to the surface eddy damping from relative wind stress, which has led to a change in the balance between the mean flow and eddies that sets the stratification.

The effect that reduced EKE under relative wind stress might have can be illustrated with a simple thought experiment. Imagine an equilibrated system is impulsively switched from resting ocean to relative wind stress without changing the mean wind stress. This impulsive switch would damp the EKE at the surface and also reduce the eddy heat transport. In terms of the residual overturning, the reduction in EKE would decrease $K$ and thus the eddy-induced bolus overturning. Since the mean wind stress has been kept constant, the Eulerian overturning will then steepen the isopycnals. This steepening will be arrested when the RMOC is again in balance with the surface heat fluxes.

(1)

[Figure 5 about here.]

As noted in Section 3.1, the circumpolar transport due to $T_{t w}$ is different between the relative and equivalent wind stress experiments. This is partly due to the more steeply sloping isopycnals moving meridional gradients into regions of lower $f$. Primarily, however, it is because the water at the southern boundary tends to be less buoyant, as a result of the changes in mean stratification and heat transport. This increase in $T_{t w}$ between the relative and equivalent wind stress experiments is consistent with the results and arguments of Hutchinson et al. (2010). However, the $1 \mathrm{~Sv}$ difference between our control experiments is considerably smaller than the $38 \mathrm{~Sv}$ between the experiments of Hutchinson et al. (2010) (see Section 5.1 for further comment). 


\section{The Mechanical Energy Budget Under Relative Wind Stress}

Before examining the sensitivity of key diagnostics to wind stress changes under different wind stress bulk formulae, we first give a short derivation of the approximate mechanical energy balance expected in a flat bottomed channel. This is a restatement of the results of AMF11 taking into account the extra "top friction" of Dewar and Flierl (1987).

In contrast to the approximate zonal momentum budget of Eq. (7), we retain the meridional component of the time-varying wind stress, i.e. $\boldsymbol{\tau}^{\prime}=$ $\left(\tau_{x}^{\prime}, \tau_{y}^{\prime}\right)$. Since $\tau_{y}^{\prime}$ is a function of the eddy velocities, it is not obvious that it makes a negligible contribution to the energy budget. Following Cessi et al. (2006) and Cessi (2008), the leading order mechanical eddy budget is expected to be

$$
\left\langle\overline{\boldsymbol{\tau} \cdot \mathbf{u}_{s}}\right\rangle \approx p_{0} r_{b}\left\langle\overline{\mathbf{u}_{b} \cdot \mathbf{u}_{b}}\right\rangle,
$$

i.e. that surface wind power input is balanced by bottom kinetic energy dissipation. After Reynolds averaging in time, this becomes

$$
\left\langle\overline{\mathcal{T}}_{x} \bar{u}_{s}\right\rangle+\left\langle\overline{\boldsymbol{\tau}^{\prime} \cdot \mathbf{u}_{s}^{\prime}}\right\rangle \approx \rho_{0} r_{b}\left\langle\bar{u}_{b}^{2}\right\rangle+\rho_{0} r_{b}\left\langle\overline{\mathbf{u}_{b}^{\prime} \cdot \mathbf{u}_{b}^{\prime}}\right\rangle
$$

where we have used that $\bar{\tau}_{y} \ll \bar{\tau}_{x}$ and $\bar{v}_{b} \ll \bar{u}_{b}$. After AMF11, and assuming only small deviations from the zonal mean, we may then use Eq. (7) to rewrite this as

$$
\left\langle\bar{\tau}_{x}\left(\bar{u}_{s}-\bar{u}_{b}\right)\right\rangle=-\left\langle\overline{\boldsymbol{\tau}^{\prime} \cdot \mathbf{u}_{s}^{\prime}}\right\rangle+\rho_{0} r_{b}\left\langle\overline{\mathbf{u}_{b}^{\prime} \cdot \mathbf{u}_{b}^{\prime}}\right\rangle
$$

Following Duhaut and Straub (2006), we use that $\left|\mathbf{U}_{10}\right| \gg\left|\mathbf{u}_{s}\right|$ to write 
$\left|\mathbf{U}_{10}-\mathbf{u}_{s}\right| \approx\left|\mathbf{U}_{10}\right|-\mathbf{u}_{s} \cdot \mathbf{k}$, where $\mathbf{k}$ is a unit vector in the direction of the atmospheric wind. Assuming that the atmospheric wind is purely zonal, eastward and constant in time, this can be further simplified to $\left|\mathbf{U}_{10}\right|-\mathbf{u}_{s} \cdot \mathbf{k} \approx$ $U_{10}-u_{s}$. With the additional assumption of constant $c_{d}$, Eq. (1) can be written as

$$
\boldsymbol{\tau}_{\text {relative }} \approx \rho_{a} c_{d}\left(U_{10}-\bar{u}_{s}-u_{s}^{\prime}\right)\left(\mathbf{U}_{10}-\overline{\mathbf{u}}_{s}-\mathbf{u}_{s}^{\prime}\right)
$$

where it is important to note that $\rho_{a} c_{d}\left(U_{10}-\bar{u}_{s}-u_{s}^{\prime}\right)$ is a scalar quantity and we have written the surface ocean velocity as the sum of its time-mean $\left(\overline{\mathbf{u}}_{s}\right)$ and a small perturbation $\left(\mathbf{u}_{s}^{\prime}\right)$.

Via Reynolds' averaging, the time average wind stress can then be approximated by

$$
\overline{\boldsymbol{\tau}}_{\text {relative }} \approx r_{s}\left(\mathbf{U}_{10}-\overline{\mathbf{u}}_{s}\right) 4 \rho_{a} c_{d} \overline{u_{s}^{\prime} \mathbf{u}_{s}^{\prime}}
$$

where $r_{s}=\rho_{a} c_{d}\left(U_{10}-\bar{u}_{s}\right)$. For the zonal component of the wind stress, the first term on the right-hand-side of Eq. (12), equivalent to $\rho_{a} c_{d}\left(U_{10}-\bar{u}_{s}\right)^{2}$, will always be considerably larger in magnitude than the second, $\rho_{a} c_{d} \overline{u_{s}^{\prime} u_{s}^{\prime}}$, and both are positive definite. The first term then reflects the well-known reduction in wind stress, with respect to the resting ocean approximation, that relative wind stress achieves with the same wind velocity. In this case primarily because the strong zonal flow of the circumpolar flow is in the same direction as the imposed atmospheric wind.

For the meridional wind stress, the first term on the right-hand-side of (12) is given by $-\rho_{a} c_{d}\left(U_{10}-\bar{u}_{s}\right) \bar{v}_{s}$ and so opposes the mean flow as an additional form of "top friction" due to Dewar and Flierl (1987). The second term on the right-hand-side is $\rho_{a} c_{d} \overline{u_{s}^{\prime} v_{s}^{\prime}}$, which is sign indefinite and so may 
act to either increase or decrease the mean meridional wind stress.

Based on Reynolds' averaging, the time-varying wind stress perturbation under relative wind stress can be approximated by

$$
\boldsymbol{\tau}_{\text {relative }}^{\prime} \approx-\rho_{a} c_{d} u_{s}^{\prime}\left(\mathbf{U}_{10}-\overline{\mathbf{u}}_{s}\right)-r_{s} \mathbf{u}_{s}^{\prime}+\rho_{a} c_{d} u_{s}^{\prime} \mathbf{u}_{s}^{\prime}-\rho_{a} c_{d} \overline{u_{s}^{\prime} \mathbf{u}_{s}^{\prime}}
$$

which time-averages to zero. An equivalent to the expression of Duhaut and Straub (2006) for the difference in power input to the ocean between the resting ocean approximation and relative wind stress forcing (their Eq. (6)) can now be derived.

By taking the dot product of Eq. (13) with the time-varying velocity and time-averaging, the following expression for the power input due to variations of the wind stress acting on variations of the ocean current results

$$
\overline{\boldsymbol{\tau}^{\prime} \cdot \mathbf{u}_{s}^{\prime}} \approx-\rho_{a} c_{d}\left(\mathbf{U}_{10}-\overline{\mathbf{u}}_{s}\right) \cdot \overline{u_{s}^{\prime} \mathbf{u}_{s}^{\prime}}-r_{s} \overline{\mathbf{u}_{s}^{\prime} \cdot \mathbf{u}_{s}^{\prime}}+\rho_{a} c_{d} \overline{u_{s}^{\prime} \mathbf{u}_{s}^{\prime} \cdot \mathbf{u}_{s}^{\prime}}
$$

Assuming that $\bar{v}_{s} \ll \bar{u}_{s}$, consistent with the equivalent assumption regarding the bottom flow in Eq. (10), and neglecting the triple correlation, this becomes

$$
\int \overline{\boldsymbol{\tau}^{\prime} \cdot \mathbf{u}_{s}^{\prime}} \approx-r_{s} \overline{u_{s}^{\prime} u_{s}^{\prime}}-r_{s} \overline{\mathbf{u}_{s}^{\prime} \cdot \overline{\mathbf{u}_{s}^{\prime}}} \approx-\frac{3}{2} r_{s} \overline{\mathbf{u}_{s}^{\prime} \cdot \mathbf{u}_{s}^{\prime}}
$$

In Eq. (15), we have further assumed that $\overline{u_{s}^{\prime} u_{s}^{\prime}} \approx \overline{\mathbf{u}_{s}^{\prime} \cdot \mathbf{u}_{s}^{\prime} / 2}$, following the argument of Hughes and Wilson (2008). This is effectively a statement that eddies are close to circular in shape. Whilst this is not strictly the case in a realistic domain with complex bathymetry, it is a reasonably good approximation in our zonally-symmetric channel domain. 


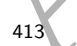

This allows Eq. (10) to be written as

$$
\left\langle\bar{\tau}_{x}\left(\bar{u}_{s}-\bar{u}_{b}\right)\right\rangle=\frac{3}{2} r_{s}\left\langle\overline{\mathbf{u}_{s}^{\prime} \cdot \mathbf{u}_{s}^{\prime}}\right\rangle+\rho_{0} r_{b}\left\langle\overline{{\overline{u^{\prime}}}_{b} \cdot \mathbf{u}_{b}^{\prime}}\right\rangle .
$$

As the surface wind speed increases, Eq. (16) indicates an increase in the available power to drive the mesoscale eddy field, as per AMF11. However, some of the extra power input goes into overcoming the additional dissipation due to relative wind stress, characterised by the additional term/with respect to Eq. (25) of AMF11.

The magnitude of the extra term can be assessed via scaling. The surface EKE is roughly an order of magnitude bigger than the bottom EKE (see Fig. 4). Taking into account the coefficients of the two terms, i.e. $\rho_{0} r_{b} \sim 1$ and $r_{s}=\rho_{a} c_{d}\left(U_{10}-\overline{u_{s}}\right) \sim 0.01$, the first term on the right-hand-side of Eq. (16) is roughly $15 \%$ of the second term.

\section{Sensitivity to Wind Speed Changes}

\subsection{Momentum and Energy Diagnostics}

[Figure 6 about here.]

As the mean wind speed increases, so too does the mean wind stress felt by the ocean (see Figs. 1c and 1d) and thus the power input to the mechanical energy budget, as per Section 4. This change in power input with wind stress is shown in Fig. 6a. Under the resting ocean approximation, the power input is always greater than when using relative wind stress with the same atmospheric wind profile. However, the difference in power input between relative and equivalent wind stress experiments is very small, $\sim$ 

${ }_{439} /$ would expect from Eq. (7) (not shown). In contrast, $T_{t w}$ varies non-linearly 440

$0.002-0.006 \mathrm{PW}$. This is surprising given the $\sim 20-35 \%$ difference in power input between resting ocean and relative wind stress formulations previously reported in the literature (see Section 1). However, in this case the relevant comparison is between resting ocean and relative wind stress experiments. The difference between these two sets of experiments is typically $\sim 10-20 \%$.

Table 2 tells us that $T_{t w}$ is slightly higher for relative wind stress than for equivalent wind stress. This means that whilst the total power input is the same for pairs of relative and equivalent wind stress experiments with the same wind stress (see Fig. 6a), the left-hand-side of Eq. (16) is slightly higher for relative wind stress. Potentially, there is a slightly larger source of mechanical energy to drive eddying motions under relative wind stress. This contradicts our intuition that relative wind stress should damp eddies. However, as Fig. 6b shows, the bottom EKE under relative wind stress is only marginally smaller than in the equivalent wind stress experiments.

In contrast to bottom EKE, the surface EKE of the relative wind stress experiments departs from the line occupied by the other two sets of experiments. This indicates that the increase in wind stress between the relative wind stress experiments, which is expected to increase EKE everywhere, is more than offset by the increased damping at the surface.

An increased wind stress can lead to an increase in the circumpolar transport by increasing $\left\langle u_{b}\right\rangle$, and thus $T_{b}$, and/or by steepening isopycnals and changing the buoyancy difference across the channel, and thus altering $T_{t w}$. The increase in $\left\langle u_{b}\right\rangle$ leads to a linear increase in $T_{b}$ with wind stress, as one with wind stress, as shown in Fig. 6c. 
At zero wind stress, the isopycnals are very close to horizontal and $T_{t w} \sim$ 0Sv. As the wind stress begins to increase $\left(\left\langle\bar{\tau}_{x}\right\rangle \leq 0.25 \mathrm{Nm}^{-2}\right)$, the isopycnals begin to tilt and $T_{t w}$ increases quasi-linearly with wind. At these low wind stresses, the additional friction due to relative wind stress is very low. At wind stresses $>0.25 \mathrm{Nm}^{-2}$, the relative wind stress experiments begin to depart from the line inhabited by the equivalent wind stress and resting ocean experiments. The increasing "top friction" leads to slightly steeper isopycnals and slightly colder water at the southern boundary. Hence, the buoyancy jump across the channel is always slightly bigger than for equivalent wind stress and resting ocean and a stronger transport results.

This sensitivity of $T_{t w}$ to changing wind stress is consistent with the results of Hutchinson et al. (2010), although at a wider range of wind stresses and in a primitive equation model. Most importantly, Fig. 6c indicates that eddy saturation, i.e. a loss of sensitivity to changing wind stress of circumpolar transport, will continue to take place under relative wind stress. However, the maximum circumpolar transport in a completely saturated current might be higher than under the resting ocean approximation.

\subsection{Sensitivity to Wind Stress of the RMOC}

[Figure 7 about here.]

Using the definition of $\Psi_{\text {upper }}$ and $\Psi_{\text {lower }}$ given in Section 3.2, Fig. 7a compares the sensitivity of the NADW and AABW cells to the changing wind stress across all of three sets of experiments. It is immediately apparent that there is very little difference in sensitivity across the range of forcing used. At high wind stress, $\bar{\tau}_{x}>0.5 \mathrm{Nm}^{-2}$, the relative wind stress experiments 
show a marginal decrease in sensitivity. However, on balance, it would seem reasonable to conclude that the use of relative wind stress does little to alter the sensitivity of the deep RMOC to changing wind.

Fig. 7b uses the definition of $\Psi_{\mathrm{m}+}$ and $\Psi_{\mathrm{m}-}$ given in Section 3.2 to assess the sensitivity of the mixed layer overturning to change in wind stress. Despite there being quite a large difference between the values of $\Psi_{\mathrm{m}+}$ for the control experiments, there is little obvious pattern to the differences in sensitivity between the three sets of experiments. This also remains true for $\Psi_{\mathrm{m}-}$. The relative wind stress experiments tend towards lower absolute values for both $\Psi_{\mathrm{m}+}$ and $\Psi_{\mathrm{m}-}$. However, this change is outside the climatological range of Southern Ocean wind stress. Therefore, it seems reasonable to conclude that the use of relative wind stress does little to alter the sensitivity of the mixed layer RMOC to changing wind stress.

The changes in the RMOC within the 3 sets of experiments can be understood in a residual mean framework using small perturbations from a control. Typically the perturbation might be brought about by a change in wind stress. However, more generally it may be any parameter or forcing that influences the system. We will consider the perturbation as being between the relative and equivalent wind stress experiments with the same mean wind stresss.

Beginning with Eq. (3) we take small perturbations and neglect terms that are quadratic, or higher, in perturbation quantities, this gives

$$
\Delta \Psi_{\mathrm{res}} \approx-\frac{\Delta \bar{\tau}_{x}}{\rho_{0} f}+\Delta K s_{0}+K_{0} \Delta s
$$

where $K_{0}$ and $s_{0}$ are the eddy diffusivity and isopycnal slope of a chosen 

sure, i.e.

$$
\frac{\Delta \Psi_{\mathrm{res}}}{\Psi_{0}^{*}} \approx \frac{\Delta \bar{\Psi}}{\Psi_{0}^{*}}+\frac{\Delta K}{K_{0}}+\frac{\Delta s}{s_{0}} .
$$

This relationship will be used below to quantify the role of relative wind stress in setting the sensitivity of the RMOC to changes in wind stress.

Fig. 7 indicates that between pairs of relative wind stress and equivalent wind stress experiments, $\Delta \Psi_{\text {res }} \approx 0$. By design, $\Delta \bar{\Psi}$ is also zero between these matched pairs of experiments. Hence, Eq. (18) reduces to

$$
\frac{\Delta s}{s_{0}} \approx-\frac{\Delta K}{K_{0}}
$$

In this case, the damping of the eddy field by "top friction" reduces $K$ and leads to an increase in s just sufficient to prevent any change in $\Psi_{\text {res }}$. The marginal differences seen between the three sets of experiments in Fig. 7 is then due to the quadratic terms that were neglected in Eqs. (17) and (18). [Figure 8 about here.]

To test the relationship between $\Delta s$ and $\Delta K$ we first diagnose the mean eddy diffusivity in each of our experiments using a simple flux gradient clo-

$$
\left\langle\overline{v^{\prime} \theta^{\prime}}\right\rangle=-K\left\langle\frac{\partial \bar{\theta}}{\partial y}\right\rangle
$$




\section{6. Discussion and Conclusions}

${ }_{531}$ The Southern Ocean plays a major role in determining the prevailing 532

The eddy diffusivity and isopycnal slope are then averaged over the central $100 \mathrm{~km}$ of the channel between depths of $500 \mathrm{~m}$ and $1500 \mathrm{~m}$. Perturbations are taken between pairs of relative wind stress and equivalent wind stress/resting ocean experiments with the same mean wind speed. This produces Fig. 8a. As expected, the difference between equivalent and relative wind stress pairs produces a set of points (blue dots) that lie close to, or on, the one-to-one line. In contrast, the difference between resting ocean and relative wind stress pairs produces a set of points (green dots) that deviate significantly from this line.

Agreement with the simple relationship of Eq. (18) is not the sole preserve of a comparison between equivalent and relative wind stress experiments in which the residual and Eulerian overturning do not change. The difference in residual overturning between the relative and resting experiments can be similarly accounted for by progressively decreasing the degree of approximation in the plotted quantities. In Fig. 8b the change in wind stress is included on the y-axis of the graph, i.e. using Eq. (18) with the assumption of no change in residual overturning by setting the left-hand-side to zero. This improves, but does not eliminate, the scatter in the green points. When the change in $\Psi_{\text {res }}$ is accounted for on the y-axis of Fig. 8c, much of the remaining scatter is removed and the comparison between the resting ocean and relative experiments also falls on the one-to-one line.

climate of the Earth system. As a result, the dynamics that govern its circu- 
lation, and the sensitivity of that circulation to forcing changes, are of great interest. Since mesoscale eddies are a crucial aspect of the circulation, the use of eddy-resolving numerical models has prevailed in understanding the Southern Ocean. These eddy-resolving models indicate a distinct decrease in sensitivity of the circumpolar transport (eddy saturation) and/or the meridional overturning (eddy compensation) to changes in wind stress. Depending on the details of the bulk formula used to calculate the stress on the ocean from the atmospheric wind, i.e. relative wind stress vs. resting ocean, it is possible to introduce an additional form of friction. This "top friction", due to Dewar and Flierl (1987), could have important consequences for the emergence of eddy saturation and eddy compensation by directly damping the eddy field at the surface of the ocean.

Experiments with a vigorously eddying ocean model show that the damping effect of relative wind stress is more important in setting the surface properties of the ocean than the $\sim 7 \%$ drop in mean wind stress. In particular, surface EKE is quife strongly reduced, whilst SST in general decreases to produce slightly cooler surface waters. As pointed out by Pacanowski (1987), the alteration of SST could go on to effect many aspects of a coupled oceanatmosphere system. In particular, whilst the experiments analysed here use a fixed flux to force SST, the actual energy balance between the ocean and atmosphere has a strong restoring component (Haney, 1971). The slightly colder SST produced under relative wind stress would likely produce stronger surface heat fluxes. When combined with changing wind stress, this might produce a positive feedback on the increased sensitivity of the RMOC (with respect to pure heat flux boundary conditions, see AMF11) that is observed 
under restoring boundary conditions (ZM14).

Even though relative wind stress damps the eddy field, a form of eddy saturation still takes place as wind stress increases. The total circumpolar transport, $T_{A C C}$, always increases with wind stress due to the strong constraint on the bottom flow from the zonal momentum (see Eq. (7)). However, it appears that the component of this transport due to thermal wind shear, $T_{t w}$, would level out at some finite value at very high wind stress (see Fig. $6 c)$. A key detail is that the final $T_{t w}$ would be higher than that achieved under the resting ocean approximation. This is due to a combination of steeper isotherms and a larger cross-channel buoyancy jump, consistent with the quasi-geostrophic experiments of Hutchinson et al. (2010).

It would be reasonable to expect that the damping of the surface eddy field may lead to an increase in the sensitivity of the RMOC to changing wind stress by reducing the ability of the system to adjust to a forcing change. However, there is only marginal change to the sensitivity of the overturning across the three sets of experiments considered here. In fact, because the generation, as well as the damping, of the ocean's eddy field is an adjustable aspect of the eirculation, the decrease in eddy diffusivity is almost offset by the increase in isopycnal slope. The result is an RMOC that has the same sensitivity as in an ocean forced using the resting ocean approximation. Relative wind stress damps the eddies adiabatically, by modifying their momentum rather than their heat content. If one considers the isopycnal framework of Walin (1982), in which diabatic transformations between density classes are used to quantify the residual overturning, it is perhaps unsurprising that relative wind stress does not play a large role in the sensitivity of 
the RMOC. This is because the surface heat fluxes are unchanged across all three sets of experiments. This is a strong constraint upon the RMOC and it is only small changes in the diabatic fluxes in temperature that the eddies themselves provide that can drive changes in the RMOC. Evidently, these diabatic eddy fluxes, and their sensitivity to wind stress, are only slightly altered under relative wind stress. This contrasts with the results of ZM14, where the damping of the eddy field by strong surface restoring of the temperature field modifies surface water mass properties diabatically. This alters the heat content of individual eddies directly and, as a result, this form of eddy damping is capable of changing the sensitivity of RMOC to wind stress changes.

Our experiments use a flat bottomed ocean in order to allow direct comparisons with the results of AMF11 and ZM14. The presence of bathymetry and continental obstacles can alter the circulation in a number of ways. In particular, bathymetry and continents concentrate EKE behind them (see, e.g., Munday et al., 2015) via modification of the channel's instability from a global to a localised form (Abernathey and Cessi, 2014). This would also focus the damping effect of using relative wind stress to these same regions, which may lead to a stronger suppression of the eddy field. Potentially, this could give rise to a stronger role for relative wind stress in setting the degree of eddy saturation/compensation in an ocean with complex bathymetry.

Bathymetry can block geostrophic contours and reduce the bottom flow to almost zero. This eliminates the contribution that these currents make to zonal transport and power input. This may lead to a larger difference in the power input between experiments conducted with the resting ocean and 

${ }_{631}$ /stress on SST increases with the wind stress and this may enhance the flux 632

relative wind stress experiments than that seen here. Blocking of geostrophic contours also leads to the generation of barotropic gyres. This may influence the response of the circumpolar transport to changes in wind forcing (Nadeau and Ferrari, 2015), as can the presence of gyres circulation to the north of a reentrant channel (Nadeau and Straub, 2009, 2012).

At the $10 \mathrm{~km}$ grid spacing used here, the eddy field is permitted, rather than strictly resolved. At this grid spacing the mature eddies are typically quite well represented, although their formation processes certainly are not. However, as noted in Section 2, this does not prevent a high degree of eddy saturation from emerging (Munday et al., 2015). Our key finding is that the use of relative wind stress results in no change in sensitivity to wind stress changes in the RMOC and the transport due to thermal wind shear still saturates. Therefore, whilst using a strictly eddy-resolving model may produce a different slope in Fig. 7, it is likely that the lack of a change in this slope between equivalent and relative wind stress experiments would remain robust. Furthermore, whilst a higher resolution model, or one with bathymetry, may produce a different saturated thermal wind transport, the important point is that this component of the transport still becomes invariant to further change at A finite wind stress.

Relative wind stress seems to be most important in setting the mixed layer properties, such as EKE and SST. As noted above, this will alter surface flux of heat and could go on to alter the uptake or release of, for example, dissolved inorganic carbon. In particular, the cooling effect of relative wind of carbon into the ocean. As the Southern Ocean is an important sink of 
anthropogenic carbon, with the future evolution of this sink being subject to debate (Le Quéré et al., 2007; Law et al., 2008; Zickfeld et al., 2008; Le Quéré et al., 2008), the role of relative wind stress in setting/modifying the carbon flux is of interest. The Ekman transport of carbon and nutrients out of the Southern Ocean feeds productivity to the north (Williams and Follows, 1998) in the form of nutrient streams (Williams et al., 2006, 2011), which may also enhance the role of relative wind stress in the carbon cycle.

\section{Acknowledgements}

DRM was supported by the British Antarctic Survey Polar Science for Planet Earth Programme. Much of this work took place whilst DRM was a PDRA in the Department of Physics at the University of Oxford and was supported by the UK Natural Environment Research Council. This work used the ARCHER UK National Supercomputing Service (http://www.archer.ac.uk). Model output is available from DRM upon request. The authors gratefully acknowledge the contributions of two anonymous reviewers whose comments improved the presentation and content of the paper.

\section{References}

Abernathey, R., Cessi, P., 2014. Topographic enhancement of eddy efficiency in baroclinic equilibration. J. Phys. Oceanogr. 44, 2107-2126, doi:10.1175/JPO-D-14-0014.1.

Abernathey, R., Marshall, J., Ferreira, D., 2011. The dependence of Southern Ocean meridional overturning on wind stress. J. Phys. Oceanogr. 41, 22612278 . 


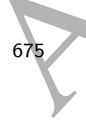

676

Badin, G., Williams, R. G., 2010. On the buoyancy forcing and residual circulation in the Southern Ocean: The feedback from Ekman and eddy transfer. J. Phys. Oceanogr. 40, 295-310.

Bryden, H. L., 1979. Poleward heat flux and conversion of available potential energy in Drake Passage. J. Mar. Res. 37, 1-22.

Cessi, P., 2008. An energy-constrained parameterization of eddy buoyancy flux. J. Phys. Oceanogr. 38, 1807-1820.

Cessi, P., Young, W. R., Polton, J. A., 2006. Control of large-scale heat transport by small-scale mixing. J. Phys. Oceanogr. 36, 1877-1894.

Dewar, W. K., Flierl, G. R., 1987. Some effects of the wind on rings. J. Phys. Oceanogr. 17, 1653-1667.

Duhaut, T. H. A., Straub, D. N., 2006. Wind stress dependence on ocean surface velocity: Implications for mechanical energy input to ocean circulation. J. Phys. Oceanogr. 36, 202-211.

Eden, C., Greatbatch, R. J., 2008. Towards a mesoscale eddy closure. Ocean Modell. 20, 223-239.

Farneti, R., Delworth, T. L., Rosati, A. J., Griffies, S. M., Zeng, F., 2010. The role of mesoscale eddies in the rectification of the Southern Ocean response to climate change. J. Phys. Oceanogr. 40, 1539-1557, doi:10.1175/2010JPO4353.1.

Ferrari, R., Wunsch, C., 2009. Ocean circulation kinetic energy: Reser- 

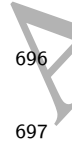

voirs, sources, and sinks. Annu. Rev. Fluid Mech. 41, 253-282, doi:10.1146/annurev.fluid.40.111406.102139.

Gill, A. E., Bryan, K., 1971. Effects of geometry on the circulation of a three-dimensional southern-hemisphere ocean model. Deep-Sea Res. 18, $685-721$.

Green, J. S., 1970. Transfer properties of the large-scale eddies and the general circulation of the atmosphere. Q. J. R. Meteorøl. Soc. 96, 157-185.

Hallberg, R., Gnanadesikan, A., 2001. An exploration of the role of transient eddies in determining the transport of a zonally reentrant current. J. Phys. Oceanogr. 31, 3312-3330.

Hallberg, R., Gnanadesikan, A., 2006. The role of eddies in determining the structure and response of the wind-driven southern hemisphere overturning: Results from the Modeling Eddies in the Southern Ocean (MESO) project. J. Phys. Oceanogr. 36, 2232-2252.

Haney, R. L., 1971. Surface thermal boundary condition for ocean circulation models. J, Phys. Oceanogr. 1, 241-248.

Hogg, A. M., Munday, D. R., 2014. Does the sensitivity of Southern Ocean circulation depend upon bathymetric details? Phil. Trans. R. Soc A 372, doi:10.1098/rsta.2013.0050.

Hüghes, C. W., Wilson, C., 2008. Wind work on the geostrophic ocean circulation: An observational study of the effect of small scales in the wind stress. J. Geophys. Res. 113, C02016, doi:10.1029/2007JC004371. 

719
Hutchinson, D. K., Hogg, A. M., Blundell, J. R., 2010. Southern Ocean response to relative velocity wind stress forcing. J. Phys. Oceanogr. 40, 326-339.

Jayne, S. R., Marotzke, J., 2002. The oceanic eddy heat transport. J. Phys. Oceanogr. 32, 3328-3345.

Johnson, G. C., Bryden, H. L., 1989. On the size of the Antarctic Circumpolar Current. Deep-Sea Res. 36, 39-53.

Kara, A. B., Rochford, P. A., Hurlburt, H. E., 2000. An optimal definition for ocean mixed layer depth. J. Geophys. Res. 105, 16 803-16821, doi:10.1029/2000JC900072.

Karsten, R., Jones, H., Marshall, J., 2002. The role of eddy transfer in setting the stratification and transport of a circumpolar current. J. Phys. Oceanogr. 32, 39-54.

Large, W. G., McWilliams, J. C., Doney, S. C., 1994. Oceanic vertical mixing: A review and a model with a nonlocal boundary layer parameterization. Rev. Geophys. 32, 363-403.

Large, W. G., Pond, S., 1981. Open ocean momentum flux measurements in moderate to strong winds. J. Phys. Oceanogr. 11, 324-336.

Law, R. M., Matear, R. J., Francey, R. J., 2008. Comment on "Saturation of the Southern Ocean $\mathrm{CO}_{2}$ sink due to recent climate change". Science 319, 570a. 
Le Quéré, C., , Rödenbeck, C., Buitenhuis, E. T., Conway, T. J., Langenfelds, ., Gomez, A., Labuschagne, C., Ramonet, M., Nakazawa, T., Metzl, N., Gillett, N., Heimann, M., 2008. Response to comments on "Saturation of the Southern Ocean $\mathrm{CO}_{2}$ sink due to recent climate change". Science 319, 570c.

Le Quéré, C., Rödenbeck, C., Buitenhuis, E. T., Conway, T. J., Langenfelds, R., Gomez, A., Labuschagne, C., Ramonet, M., Nakazawa, T., Metzl, N., Gillett, N., Heimann, M., 2007. Saturation of the Southern Ocean $\mathrm{CO}_{2}$ sink due to recent climate change. Science 316 (1735-1738), 1735-1738, doi:19.1126/science.1136188.

Marshall, J., Adcroft, A., Hill, C., Perelman, L., Heisey, C., 1997a. A finite volume, incompressible Navier-Stokes model for studies of the ocean on parallel computers. J. Geophys. Res. 102, 5753-5766.

Marshall, J., Hill, C., Perelman, L., Adcroft., A., 1997b. Hydrostatic, quasihydrostatic, and non-hydrostatic ocean modeling. J. Geophys. Res. 102, $5733-5752$.

Marshall, J., Radko, T., 2003. Residual-mean solutions for the Antarctic Circumpolar Current and its associated overturning circulation. J. Phys. Oceanogr. 33, 2341-2354.

Meijers, A. J., Bindoff, N. L., Roberts, J. L., 2007. On the total, mean, rand eddy heat and freshwater transports in the southern hemisphere of a ${ }_{741} \frac{1}{8}^{\circ} \times \frac{1}{8}^{\circ}$ global ocean model. J. Phys. Oceanogr. 37, 277-295. 


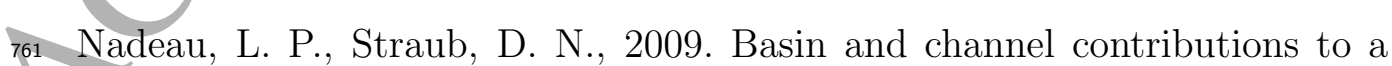

Meredith, M. P., Woodworth, P. L., Chereskin, T. K., Marshall, D. P., Allison, L. C., Bigg, G. R., Donohue, K., Heywood, K. J., Hughes, C. W., Hibbert, A., Hogg, A. M., Johnson, H. L., King, B. A., Leach, H., Lenn, Y., Morales-Maqueda, M. A., Munday, D. R., Naveira-Garabato, A. C., Provost, C., Sprintall, J., 2011. Sustained monitoring of the Southern Ocean at Drake Passage: past achievements and future priorities. Rev. Geophys. 49, RG4005, doi:10.1029/2010RG000348.

Morrison, A. K., Hogg, A. M., 2013. On the relationship between Southern Ocean overturning and ACC transport. J. Phys. Oceanogr. 43, 140-148.

Munday, D. R., Johnson, H. L., Marshall, D. P., 2013. Eddy saturation of equilibrated circumpolar currents. J. Phys. Oceanogr. 43, 507-532.

Munday, D. R., Johnson, H. L., Marshall, D. P., 2015. The role of ocean gateways in the dynamics and sensitivity to wind stress of the early Antarctic Circumpolar Current. Paleoceanography 30, doi:10.1002/2014PA002675.

Munk, W. H., Palmén, E., 1951. Note on the dynamics of the Antarctic Circumpolar Current. Tellus 3, 53-55.

Nadeau, L. P., Ferrari, R., 2015. The role of closed gyres in setting the zonal transport of the Antarctic Circumpolar Current. J. Phys. Oceanogr. 45, 1491-1509, doi:10.1175/JPO-D-14-0173.1. model Antarctic Circumpolar Current. J. Phys. Oceanogr. 39, 986-1002.

763 Nadeau, L. P., Straub, D. N., 2012. Influence of wind stress, wind stress curl, 
and bottom friction on the transport of a model Antarctic Circumpolar Current. J. Phys. Oceanogr. 42, 207-222.

Pacanowski, R. C., 1987. Effect of equatorial currents on surface stress. J. Phys. Oceanogr. 17, 833-838.

Prandtl, L., 1925. Bericht über Untersuchungen zur ausgebildeten Turbullenz. Z. Angew. Math. Mech. 5, 136-139.

Stone, P. H., 1972. A simplified radiative-dynamical model for the static stability of rotating atmospheres. J. Atmos. Sci. 29, 405-418.

Straub, D. N., 1993. On the transport and angular momentum balance of channel models of the Antarctic Circumpolar Current. J. Phys. Oceanogr. 23, 776-782.

Tansley, C. E., Marshall, D. P., 2001. On the dynamics of wind-driven circumpolar currents. J. Phys. Oceanogr. 31, 3258-3273.

Viebahn, J., Eden,C., 2010. Towards the impact of eddies on the response of the Southern Ocean to climate change. Ocean Modell. 34, 150-165.

Walin, G., 1982. On the relation between sea-surface heat flow and thermal circulation in the ocean. Tellus 34, 187-195.

Williams, R. G., Follows, M. J., 1998. The Ekman transfer of nutrients and maintenance of new production over the North Atlantic. Deep-Sea Res. 45, 461-489. 

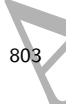
${ }_{804}$ uration of the Southern Ocean $\mathrm{CO}_{2}$ sink due to recent climate change".

Williams, R. G., McDonagh, E., Roussenov, V. M., Torres-Valdes, S., King, B., Sanders, R., Hansell, D. A., 2011. Nutrient streams in the North Atlantic: Advective pathways of inorganic and dissolved organic nutrients. Global Biogeochem. Cycles 25, GB4008, doi:10.1029/2010GB003853.

Williams, R. G., Roussenov, V., Follows, M. J., 2006. Nutrient streams and their induction into the mixed layer. Global Biogeochem. Cycles 30, GB1016, doi:10.1029/2005GB002586.

Wunsch, C., 1998. The work done by the wind on the oceanic general circulation. J. Phys. Oceanogr. 28, 2332-2340.

Wunsch, C., Ferrari, R., 2004. Vertical mixing, energy, and the general circulation of the oceans. Annu. Rey. Fluid Mech. 36, 281-314.

Zhai, X., Greatbatch, R. J., 2007. Wind work in a model of the northwest Atlantic Ocean. Geophys. Res. Lett.34, L04606, doi:10.1029/2006GL028907.

Zhai, X., Johnson, H. L., Marshall, D. P., Wunsch, C., 2012. On the wind power input to the ocean general circulation. J. Phys. Oceanogr. 42, 13571365 .

Zhai, X., Munday, D. R., 2014. Sensitivity of Southern Ocean overturning to wind stress changes: Role of surface restoring time scales. Ocean Modell. 84, 12-25, doi:10.1016/j.ocemod.2014.09.004.

Zickfeld, K., Fyfe, J. C., Eby, M., Weaver, A. J., 2008. Comment on "SatScience 319, 570b. 


\section{List of Figures}

1 Model forcing as described in the text. (a) Northern boundary temperature restoring profile, (b) surface heat flux (positive into ocean), (c) atmospheric wind profile, (d) corresponding surface wind stress under the resting ocean approximation.

2 RMOC $(\mathrm{Sv})$ for the three control experiments with $U_{0}=$ $12 \mathrm{~m} \mathrm{~s}^{-1}$. Black contours are the zonal-time-average potential temperature $\left({ }^{\circ} \mathrm{C}\right)$ and the colours are the RMOC with red indicating clockwise flow. The grey contour is the mixed layer depth from the KPP parameterisation. . . . . . . . . . . . 41

3 Surface EKE $\left(\mathrm{cm}^{2} \mathrm{~s}^{-1}\right)$ for the control wind forcing with $U_{0}=$ $12 \mathrm{~ms}^{-1}$. . . . . . . . . . . . . . . 42

4 Depth profiles of horizontally-averaged quantities. (a) EKE and (b) temperature variance. Medium-weight lines are the three control experiments with $U_{\theta}=12 \mathrm{~m} \mathrm{~s}^{-1}$, thin lines have $U_{0}=0 \mathrm{~m} \mathrm{~s}^{-1}$, and heavy lines have $U_{0}=20 \mathrm{~m} \mathrm{~s}^{-1} \ldots \ldots . . .43$

5 Zonally-averaged potential temperature for the three control states with $U_{0}=12 \mathrm{~m} \mathrm{~s}^{-1}$. Green contours are the resting ocean control, blue contours are the equivalent wind stress control, and red contours are the relative wind stress control. . 44

6 Sensitivity to wind stress changes of energy and momentum diagnostics. (a) Power input vs. maximum wind stress, (b) surface/bottom EKE vs. power input, (c) "baroclinic" transport, as per $T_{t w}$ vs. maximum wind stress. . . . . . . . . .

7 Sensitivity of the RMOC to changing wind stress across all experiments. (a) Maximum/minimum RMOC 100km south of the northern restoring zone and below $500 \mathrm{~m}$, (b) maximum/minimum RMOC in upper 500m (minimum also restricted to southern half of domain). 
8 Quantitative tests of residual mean relationship between changes in eddy diffusivity and isopycnal slope. (a) Excluding any wind stress changes, as per Eq. (19), (b) including wind stress changes, but excluding $\Delta \Psi_{\text {res }}$, (c) full relationship as per Eq. (18). Blue dots are the difference between the equivalent and relative wind stress experiments, green dots are the difference between the resting ocean and relative wind stress experiments. The dotted lines cross at the origin and the solid line has a gradient of $1 \ldots \ldots . \ldots . . \ldots 47$ 
a) $T_{N}$

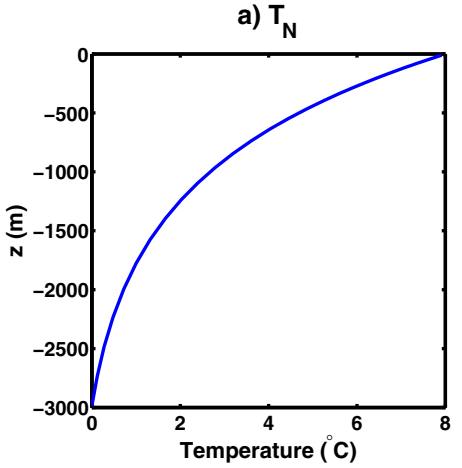

c) $\mathrm{U}_{10}$

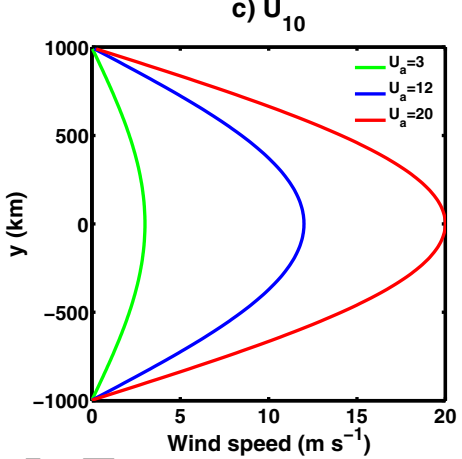

b) $\mathbf{Q}$

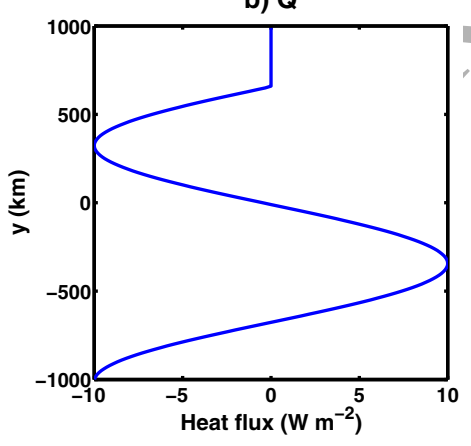

d) $\tau_{\text {resting }}$

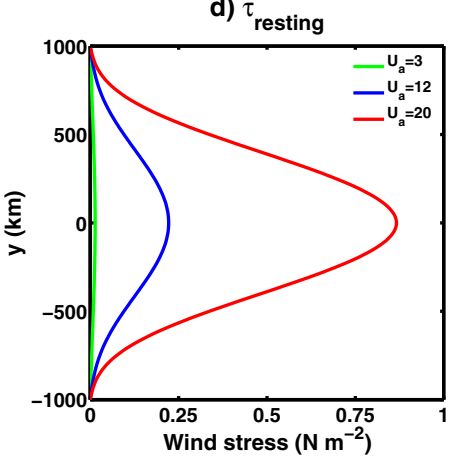

Figure 1: Model forcing as described in the text. (a) Northern boundary temperature restoring profile, (b) surface heat flux (positive into ocean), (c) atmospheric wind profile, (d) corresponding surface wind stress under the resting ocean approximation. 
a) Relative wind stress

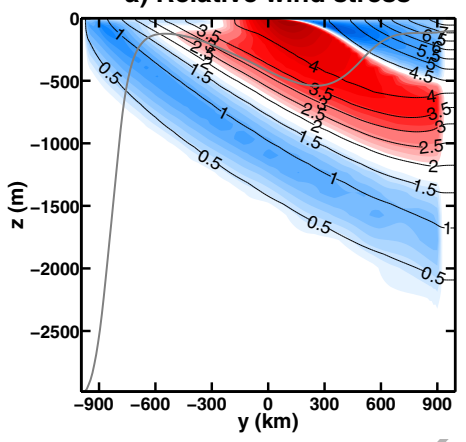

b) Equivalent wind stress

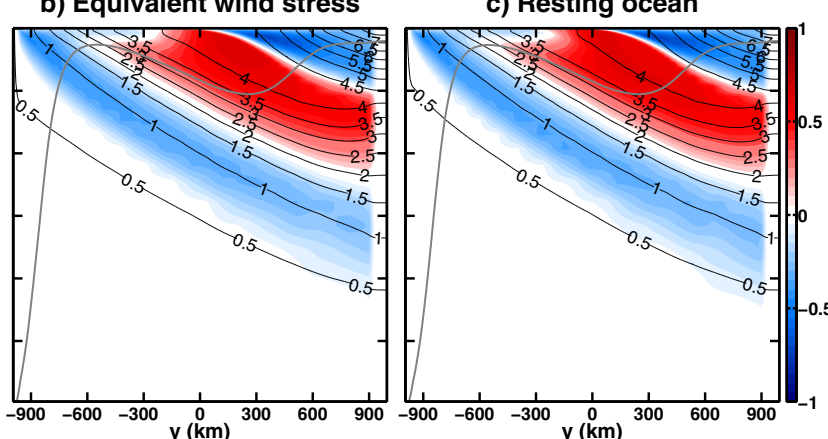

Figure 2: RMOC (Sv) for the three control experiments with $U_{0}=12 \mathrm{~m} \mathrm{~s}^{-1}$. Black contours are the zonal-time-average potential temperature $\left({ }^{\circ} \mathrm{C}\right)$ and the colours are the RMOC with red indicating clockwise flow. The grey contour is the mixed layer depth from the KPP parameterisation. 

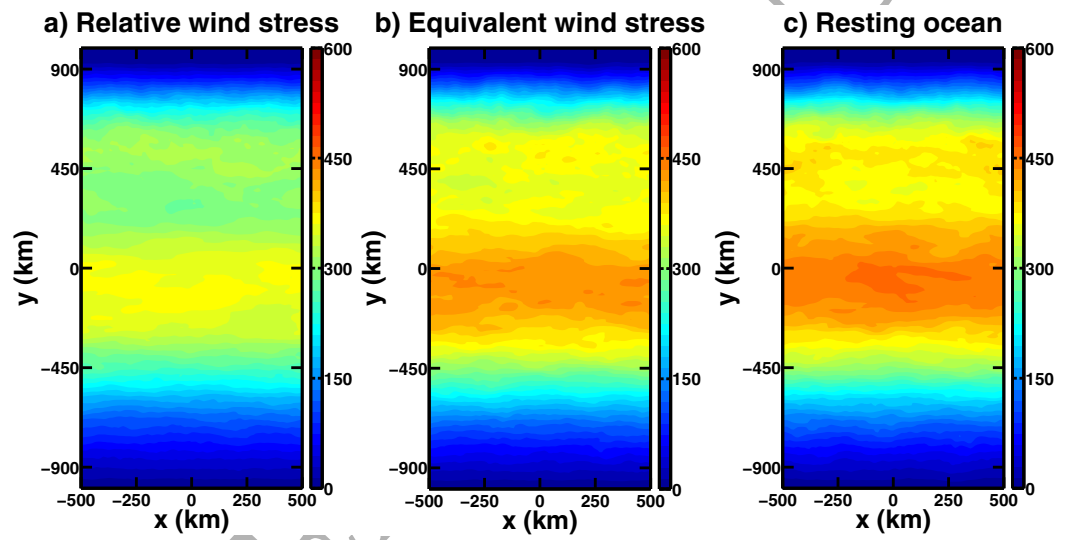

Figure 3: Surface EKE $\left(\mathrm{cm}^{2} \mathrm{~s}^{-1}\right)$ for the control wind forcing with $U_{0}=12 \mathrm{~m} \mathrm{~s}^{-1}$. 

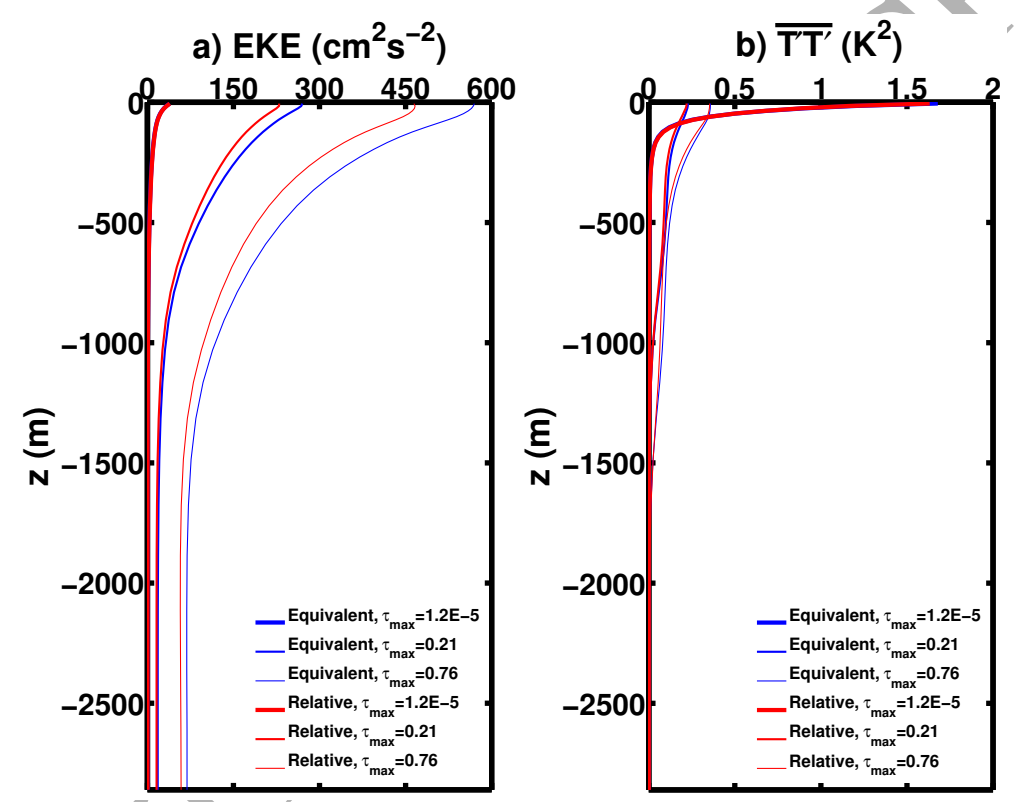

Figure 4: Depth profiles of horizontally-averaged quantities. (a) EKE and (b) temperature variance. Medium-weight lines are the three control experiments with $U_{0}=12 \mathrm{~m} \mathrm{~s}^{-1}$, thin lines have $U_{0}=0 \mathrm{~ms}^{-1}$, and heavy lines have $U_{0}=20 \mathrm{~ms}^{-1}$ 


\section{Temperature contours}

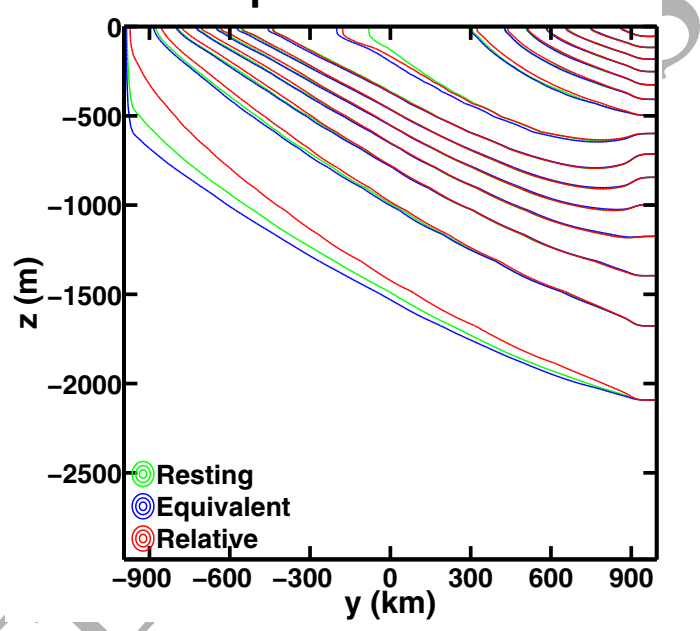

Figure 5: Zonally-averaged potential temperature for the three control states with $U_{0}=$ $12 \mathrm{~m} \mathrm{~s}^{-1}$. Green contours are the resting ocean control, blue contours are the equivalent wind stress control, and red contours are the relative wind stress control. 


\section{a) Power input}

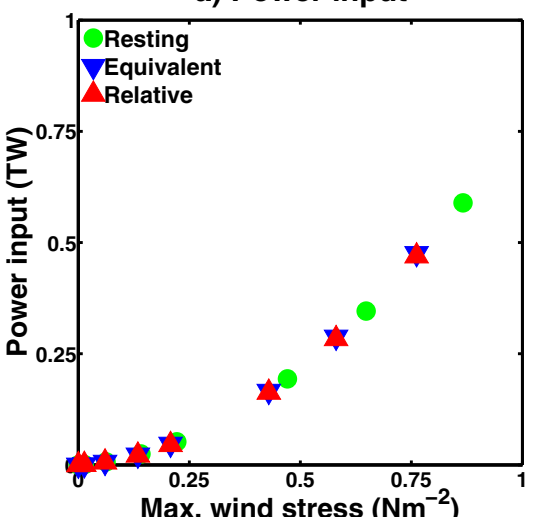

b) EKE

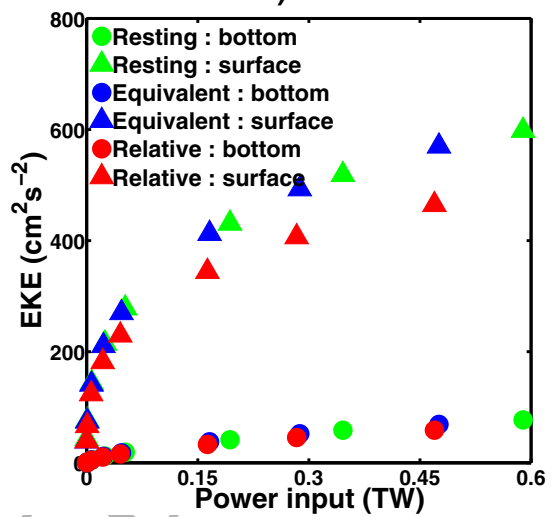

C) Baroclinc transport

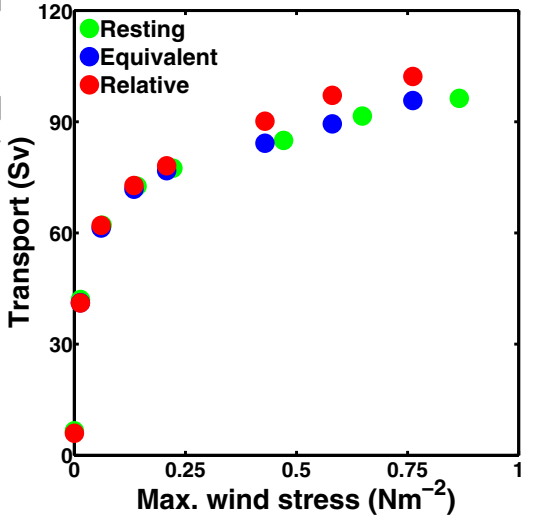

Figure 6: Sensitivity to wind stress changes of energy and momentum diagnostics. (a) Power input vs. maximum wind stress, (b) surface/bottom EKE vs. power input, (c) "baroclinic" transport, as per $T_{t w}$ vs. maximum wind stress. 
a) Deep RMOC

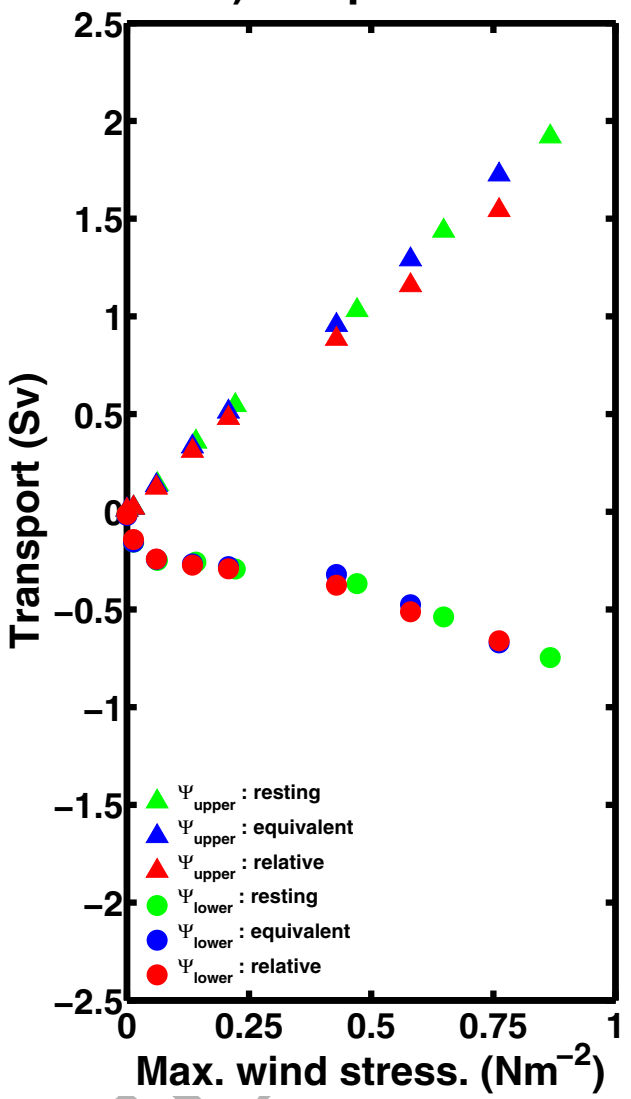

b) Mixed layer RMOC

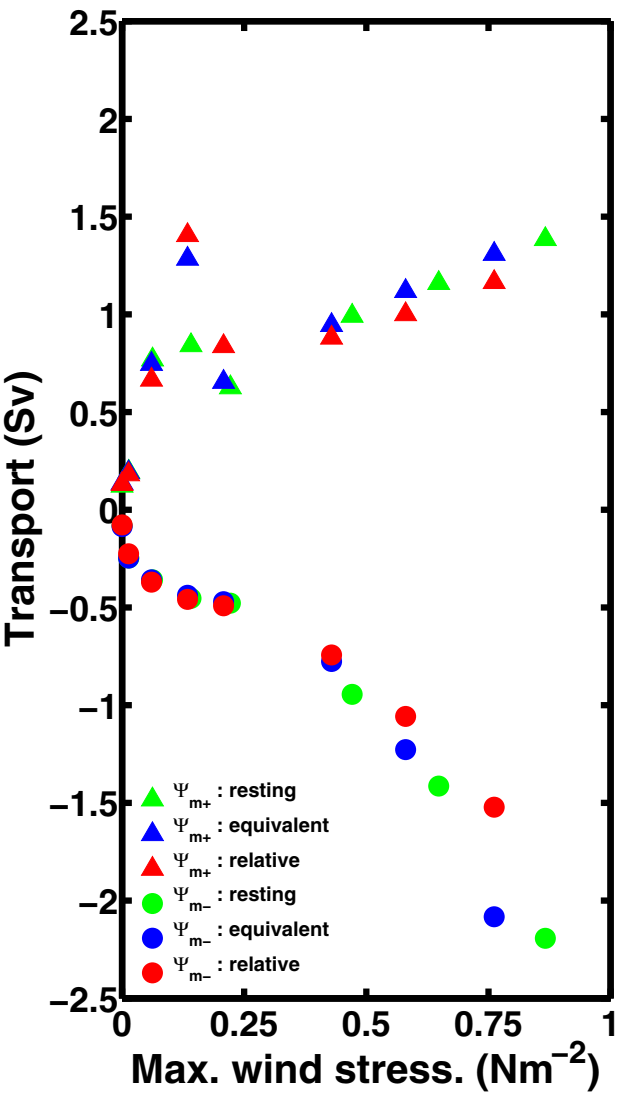

Figure 7: Sensitivity of the RMOC to changing wind stress across all experiments. (a) Maximum/minimum RMOC $100 \mathrm{~km}$ south of the northern restoring zone and below $500 \mathrm{~m}$, (b) maximum/minimum RMOC in upper 500m (minimum also restricted to southern half of domain). 
a) Excluding wind change

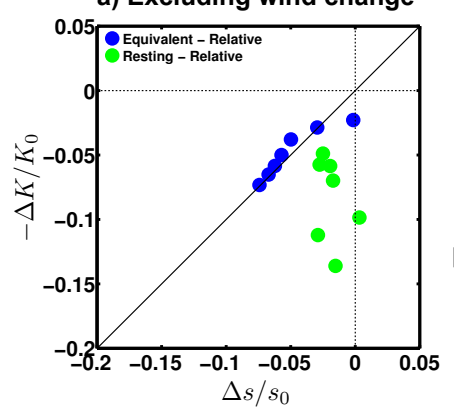

b) Including wind change

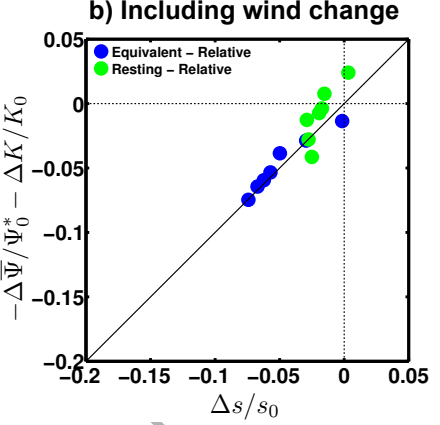

c) Including RMOC change

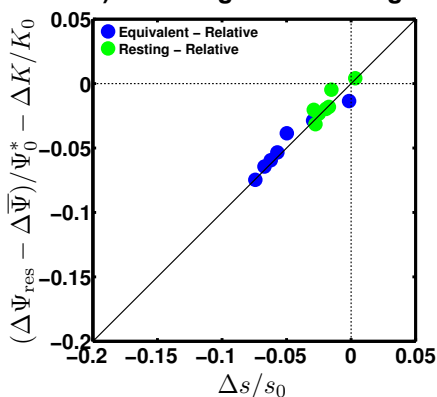

Figure 8: Quantitative tests of residual mean relationship between changes in eddy diffusivity and isopycnal slope. (a) Excluding any wind stress changes, as per Eq. (19), (b) including wind stress chànges, but excluding $\Delta \Psi_{\text {res }}$, (c) full relationship as per Eq. (18). Blue dots are the difference between the equivalent and relative wind stress experiments, green dots are the difference between the resting ocean and relative wind stress experiments. The dotted lines cross at the origin and the solid line has a gradient of 1. 


\section{${ }_{844}$ List of Tables}

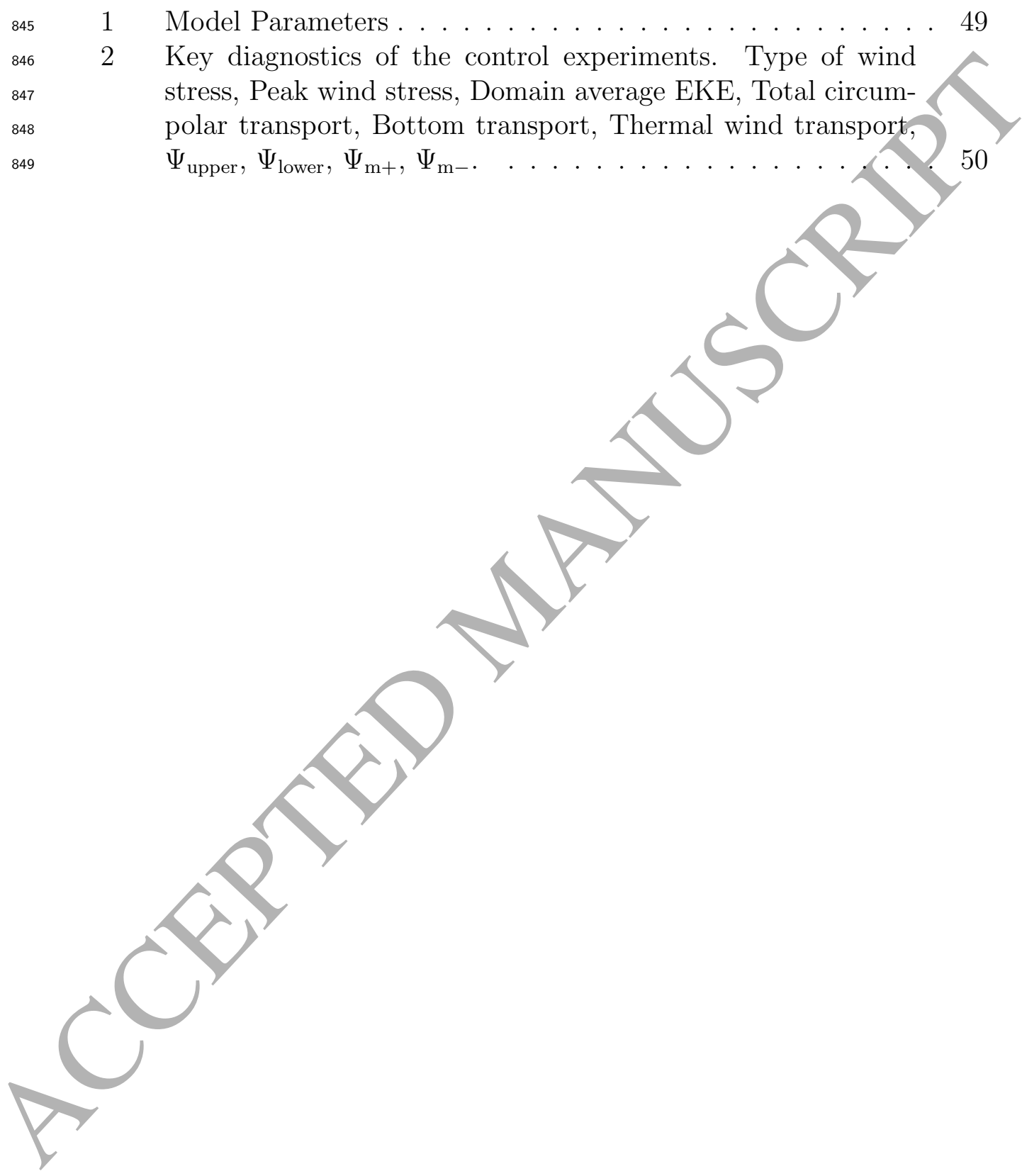


Table 1: Model Parameters

\begin{tabular}{c|c|c|c}
\hline Parameter & Symbol & Value & Units \\
\hline Domain size & $L_{x}, L_{y}$ & 1000,1990 & $\mathrm{~km}$ \\
Latitude of sponge edge & $L_{\text {sponge }}$ & 1890 & $\mathrm{~km}$ \\
Domain depth & $H$ & 2985 & $\mathrm{~m}$ \\
Reference density & $\rho_{0}$ & 1000 & $\mathrm{~kg} \mathrm{~m}^{-3}$ \\
Thermal expansion coefficient & $\alpha$ & $2 \times 10^{-4}$ & $\mathrm{~K}^{-1}$ \\
Coriolis parameter & $f_{0}$ & $-1 \times 10^{-4}$ & $\mathrm{~s}^{-1}$ \\
Gradient in Coriolis parameter & $\beta$ & $1 \times 10^{-11}$ & $\mathrm{~m}^{-1} \mathrm{~s}^{-1}$ \\
Surface heat flux magnitude & $Q_{0}$ & 10 & $\mathrm{~W} \mathrm{~m}^{-2}$ \\
Control wind speed & $U_{0}$ & 12 & $\mathrm{~m} \mathrm{~s}^{-1}$ \\
Bottom drag coefficient & $r_{b}$ & $1.1 \times 10^{-3}$ & $\mathrm{~m} \mathrm{~s}^{-1}$ \\
Sponge restoring timescale & $t_{\text {sponge }}$ & 7 & $\mathrm{days}^{-10}$ \\
Sponge vertical scale & $h_{e}$ & 1000 & $\mathrm{~m}$ \\
Horizontal grid spacing & $\Delta x, \Delta y$ & 10 & $\mathrm{~km}$ \\
Vertical grid spacing & $\Delta z$ & $10-250$ & $\mathrm{~m}^{-1}$ \\
Vertical diffusivity $(\theta)$ & $\kappa_{\mathrm{v}}$ & $10^{-5}$ & $\mathrm{~m}^{2} \mathrm{~s}^{-1}$ \\
Horizontal diffusivity $(\theta)$ & $\kappa_{h}$ & 0 & $\mathrm{~m}^{4} \mathrm{~s}^{-1}$ \\
Vertical viscosity $(\mathbf{u})$ & $A_{\mathrm{v}}$ & $10^{-3}$ & $\mathrm{~m}^{2} \mathrm{~s}^{-1}$ \\
Horizontal hyperviscosity $(\mathbf{u})$ & $A_{4}$ & $10^{10}$ & $\mathrm{~m}^{4} \mathrm{~s}^{-1}$ \\
\hline
\end{tabular}


Table 2: Key diagnostics of the control experiments. Type of wind stress, Peak wind stress, Domain average EKE, Total circumpolar transport, Bottom transport, Thermal wind transport, $\Psi_{\text {upper }}, \Psi_{\text {lower }}, \Psi_{\mathrm{m}+}, \Psi_{\mathrm{m}-\text {, }}$

\begin{tabular}{c|c|c|c|c|c|c|c|c|c}
\hline Experiment & $\begin{array}{c}\tau_{0} \\
\left(\mathrm{Nm}^{-2}\right)\end{array}$ & $\begin{array}{c}\text { EKE } \\
\left(\mathrm{cm}^{2} \mathrm{~s}^{-2}\right)\end{array}$ & $\begin{array}{c}T_{A C C} \\
(\mathrm{~Sv})\end{array}$ & $\begin{array}{c}T_{b} \\
(\mathrm{~Sv})\end{array}$ & $\begin{array}{c}T_{t w} \\
(\mathrm{~Sv})\end{array}$ & $\begin{array}{c}\Psi_{\mathrm{u}} \\
(\mathrm{Sv})\end{array}$ & $\begin{array}{c}\Psi_{1} \\
(\mathrm{~Sv})\end{array}$ & $\begin{array}{c}\Psi_{\mathrm{m}+} \\
(\mathrm{Sv})\end{array}$ & $\begin{array}{c}\Psi_{\mathrm{m}-} \\
(\mathrm{Sv})\end{array}$ \\
\hline Relative & 0.208 & 43 & 600 & 522 & 78 & 0.48 & -0.29 & 0.84 & -0.49 \\
Equivalent & 0.208 & 50 & 599 & 522 & 77 & 0.51 & -0.28 & 0.65 & -0.47 \\
Resting & 0.222 & 52 & 629 & 551 & 78 & 0.54 & -0.30 & 0.63 & -0.48 \\
\hline
\end{tabular}

